\title{
The chick somitogenesis oscillator is arrested before all paraxial mesoderm is segmented into somites
}

\author{
Gennady Tenin', David Wright', Zoltan Ferjentsik', Robert Bone, Michael J McGrew², Miguel Maroto ${ }^{\text {** }}$
}

\begin{abstract}
Background: Somitogenesis is the earliest sign of segmentation in the developing vertebrate embryo. This process starts very early, soon after gastrulation has initiated and proceeds in an anterior-to-posterior direction during body axis elongation. It is widely accepted that somitogenesis is controlled by a molecular oscillator with the same periodicity as somite formation. This periodic mechanism is repeated a specific number of times until the embryo acquires a defined specie-specific final number of somites at the end of the process of axis elongation. This final number of somites varies widely between vertebrate species. How termination of the process of somitogenesis is determined is still unknown.

Results: Here we show that during development there is an imbalance between the speed of somite formation and growth of the presomitic mesoderm (PSM)/tail bud. This decrease in the PSM size of the chick embryo is not due to an acceleration of the speed of somite formation because it remains constant until the last stages of somitogenesis, when it slows down. When the chick embryo reaches its final number of somites at stage HH 24-25 there is still some remaining unsegmented PSM in which expression of components of the somitogenesis oscillator is no longer dynamic. Finally, we identify a change in expression of retinoic acid regulating factors in the tail bud at late stages of somitogenesis, such that in the chick embryo there is a pronounced onset of Raldh2 expression while in the mouse embryo the expression of the RA inhibitor Cyp26A1 is downregulated.

Conclusions: Our results show that the chick somitogenesis oscillator is arrested before all paraxial mesoderm is segmented into somites. In addition, endogenous retinoic acid is probably also involved in the termination of the process of segmentation, and in tail growth in general.
\end{abstract}

\section{Background}

Somitogenesis is the earliest sign of segmentation in the developing vertebrate embryo [1-3]. During this process vertebrate embryos generate transitory structures called somites that later in development give rise to the vertebral column, most of the skeletal musculature and much of the dermis [4]. This process starts very early soon after gastrulation has initiated and proceeds in an anterior-to-posterior direction during body axis elongation. The elongation of the body axis of the vertebrate embryo has been traditionally divided into two phases termed primary and secondary body formation $[5,6]$. During the first phase the somites and other types of

\footnotetext{
* Correspondence: m.maroto@dundee.ac.uk

'Division of Cell and Developmental Biology, College of Life Sciences, University of Dundee, Dow Street, Dundee, UK
}

mesoderm are derived from cells that have traversed the primitive streak (in amniotes) or its equivalent (in anamniote vertebrates). Fate mapping analyses have shown that the primitive streak contains distinct stem cell populations in specific domains along the antero-posterior axis of the streak [7-9]. During secondary body formation the tail bud is the source of somitic mesoderm precursors $[10,11]$. At first considered to be a homogeneous blastema of tissue, lineage analysis has since shown that distinct stem cell populations also exist in specific domains within the tail bud, as proposed by Pasteels [12], and they are capable of contributing to multiple tissue types [5,13-20].

During axis elongation two parallel bands of paraxial mesoderm tissue known as the unsegmented or presomitic mesoderm (PSM) migrate out from the primitive

\section{()


streak (or tail bud) and come to lie alongside the notochord. Groups of cells at the most rostral end of each PSM bud off with a remarkable periodicity and synchronisation as an epithelial sphere of cells to form the new somite. It is widely accepted that this process is controlled by a molecular oscillator [21] that drives periodic waves of gene expression caudo-rostrally through the PSM with the same periodicity as somite formation. In fact, in recent years the community has reported the discovery and characterization of a considerable number of these so-called clock genes in a variety of vertebrate species, all of which are components of the Notch, Wnt or FGF pathways [22-24]. This periodic mechanism is repeated a specific number of times until the embryo acquires a defined species-specific final number of somites at the end of the process of axis elongation. This final number of somites varies widely between vertebrate species: $38-39$ somites in the human embryo, 51-53 in the chick embryo, 62-65 in the mouse embryo and several hundred somites in snake embryos of different species [25].

How termination of the process of somitogenesis, and tail bud growth in general, are determined is still unknown. Several mechanisms have been proposed to contribute including an overall control of somite number exerted by the embryo as a whole [26], a localised cell death overtaking the process [26,27], inadequacies in the local environment or in the cells themselves [28] or suppression of the epithelial-mesenchymal transition required for gastrulation-like movements [29]. In this study we analysed the anatomy of the tail bud at the end of the process and went on to investigate this tissue with respect to apoptosis, the somitogenesis oscillator and the regulation by endogenous retinoic acid (RA) of factors associated to the growth and proliferation of the precursor stem cells.

\section{Results \\ PSM elongation is not happening at the same speed as somite formation}

To investigate the cessation of the process of somitogenesis in the chick tail bud it is important first to know if indeed, as previously proposed, the somites extend to the tip of the tail at HH stage 22 [30] or whether this is not the case and there remains some unsegmented PSM $[26,28]$. The somites extending close to the tip would indicate there is an imbalance between the speed of axis elongation and the recruitment of new cells to become part of the PSM tissue, while if the paraxial mesoderm remains unsegmented this would indicate that the somitogenesis oscillator stops producing somites at a specific stage of development. Thus, we collected chick embryos ranging in development from $\mathrm{HH}$ stage 20 to 27 and stained them by in situ hybridisation either with $c$ - $T b x 6$, a probe specific for the non-segmented PSM ( $\mathrm{n}=14$, Figure 1A-J), or with c-Dact $2 / c-M y o D$ a combination of probes to specifically label the most recently formed somites $(n=21$, Figure $1 \mathrm{~K}-\mathrm{O})$. As development proceeds we observed that the domain of $c-T b x 6$ expression in the non-segmented mesoderm becomes progressively smaller in the tail bud until it disappears at $\mathrm{HH}$ stage 26-27. Concurrently, we detected the domain of $c$-Dact $2 / c-M y o D$ expression in the last formed somites gradually moving closer to the end of the tail bud until it almost reached the tip at stage 26-27 $\mathrm{HH}$. We concluded from these results that in fact at the end of somitogenesis the somites nearly reach the tip of the tail bud. We then measured the length of the PSM, the diameter of the last formed somite and the ratio PSM length versus last somite diameter in a large number of embryos ranging from $\mathrm{HH}$ stage 10-24 $(\mathrm{n}=105)$. These graphical representations show that until HH stage 14 both parameters increase slightly and then decrease as development proceeds further (Figure 1P, Q; [31]) indicating that from $\mathrm{HH}$ stage 14 the elongation of the chick PSM tissue is not happening at the same speed as somite formation. We reasoned that the observed imbalance could be produced by an acceleration in the speed of somite formation or the result of a progressive reduction in the growth/number of precursor stem cells due to changes in their proliferation status and/or apoptosis. We investigated if either of these mechanisms indeed contributes to the cessation of this process.

\section{Deceleration of the speed of somite formation}

To determine if an acceleration in the speed of somitogenesis at late stages contributes to the loss of PSM tissue and the termination of somite formation we analysed a large batch $(n=105)$ of $\mathrm{HH}$ stage 10 embryos incubated for specific periods of time and then recording the number somites formed (Figure 2A). A regression analysis allowed us to conclude that at least until approx. HH stage 21 the periodicity of somite formation remains constant at 90 minutes. According to the results only the speed of formation of the last 5-8 somites is different to the rest. Interestingly their formation pace does not seem to get faster but in fact gets progressively slower. To confirm the existence of this deceleration in the speed of somite formation we performed an in vitro experiment in which the tail of a chick embryo is split in two halves, one half is immediately fixed and the second half is cultured for $90 \mathrm{~min}$ utes, and then both samples are analysed by in situ hybridisation for the expression of a clock gene, such as the Notch target gene $c-L f n g$. When this analysis was performed using samples of early stages of somitogenesis, such as HH stage 19-20, the two halves displayed 


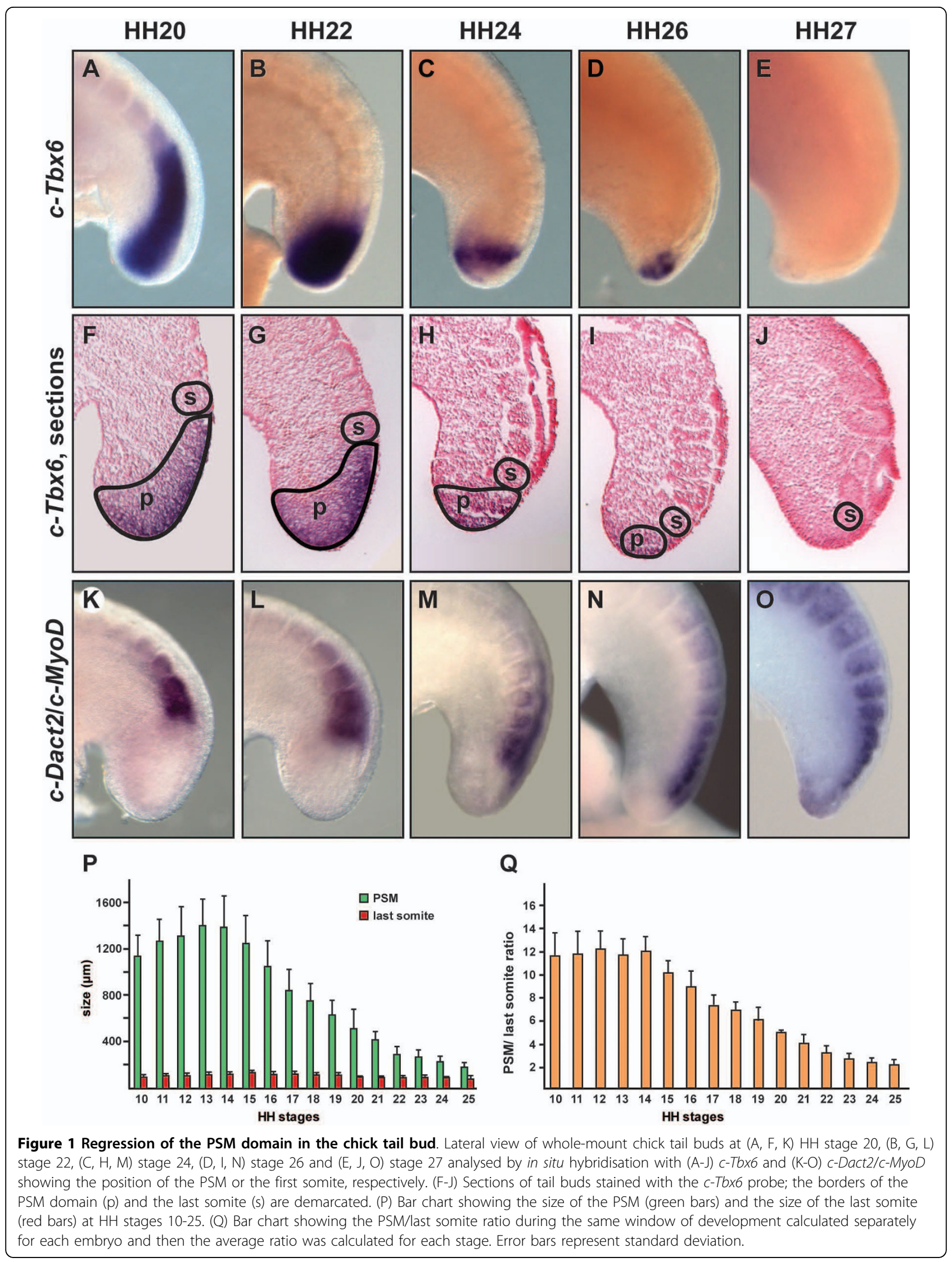




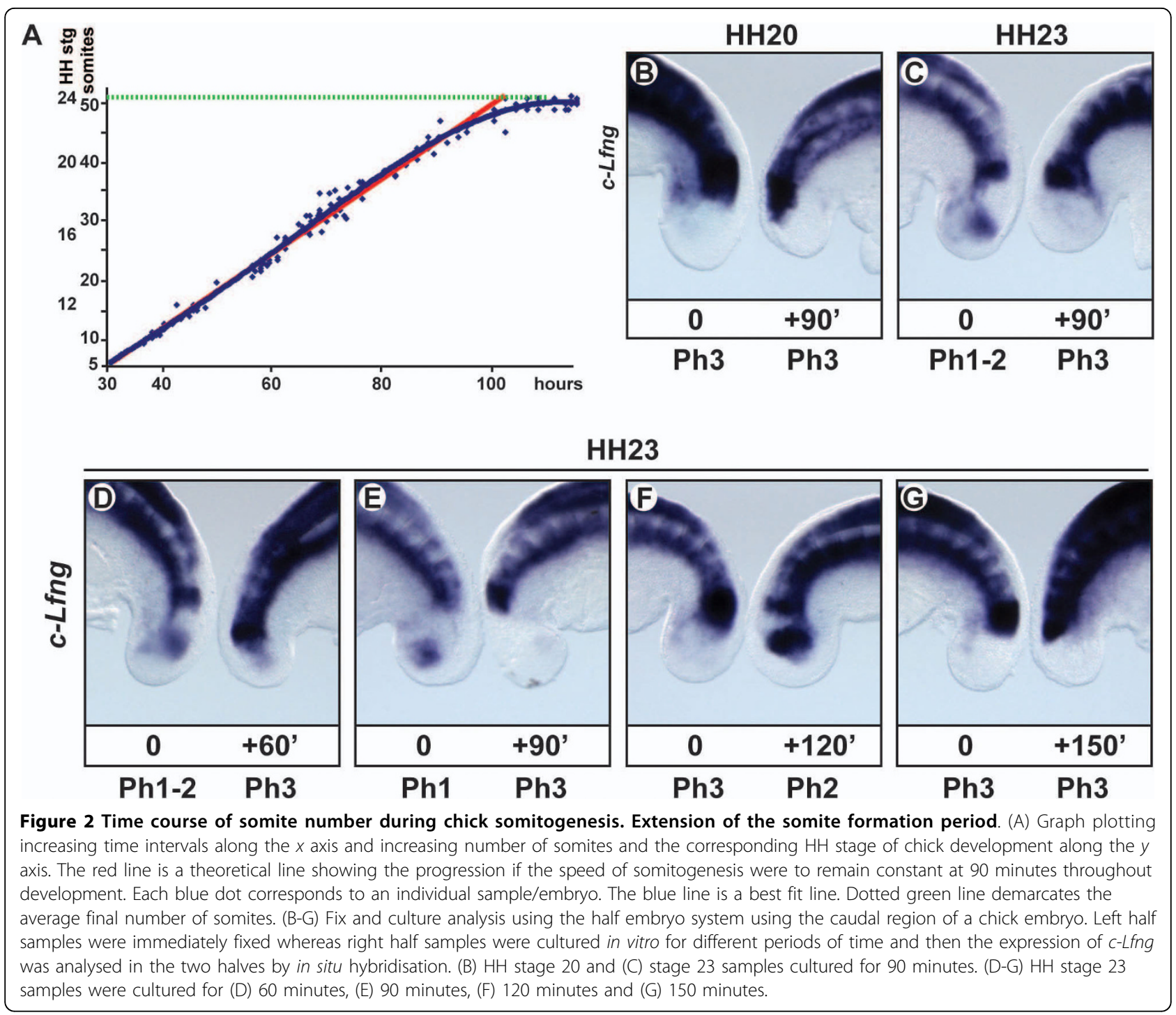

the same pattern of expression of $c-L f n g$ and a new somite was apparent in the cultured half, consistent with a periodicity of somite formation of 90 minutes ( $\mathrm{n}=15$, Figure 2B; [32]). However, when the same experiment was repeated with late stages of somitogenesis, such as $\mathrm{HH}$ stage 23 , the two halves displayed different patterns of expression of $c$-Lfng suggesting that the cultured half has not been able to complete the whole cycle in 90 minutes $(n=9$, Figure $2 C$, [33]). To confirm this result we repeated the experiment and cultured the samples for different periods of time ranging from 60 to 150 minutes $(\mathrm{n}=42)$. We found that the two HH stage 23 halves displayed the same pattern of expression only after one half had been cultured for 150 minutes longer than the other (Figure 2D-G), which is therefore the time required to make a new somite at this stage of development. Thus, the imbalance between the speed of axis elongation and the recruitment of new cells to become part of the non-segmented mesoderm cannot be due to acceleration in the speed of somitogenesis.

The somitogenesis oscillator is arrested at late stages of development

Our results also showed that chick embryos produce a total of 51-53 somites that in most cases are already formed by $\mathrm{HH}$ stage 24-25 (dotted green line in Figure 2A). Curiously, at those stages there is still a remaining population of $c-T b x 6$ positive PSM cells in the tail bud (Figure $1 \mathrm{C}, \mathrm{D}, \mathrm{H}, \mathrm{I}$ ), suggesting that the last PSM tissue probably does not contribute to the formation of new somites. To investigate this possibility we decided to explore the activity of the somitogenesis oscillator by examining the expression of Notch regulated cyclic genes, such as $c$-Lfng, in batches of embryos at several developmental stages to see if different patterns of expression could be observed, which would be indicate 
that the oscillator was still operational. At $\mathrm{HH}$ stage 22 $(\mathrm{n}=10)$, when the embryo is still forming somites, we found clear different patterns of expression of $c$-Lffng in the PSM (Figure 3A, B), consistent with the idea that at this stage the expression is still dynamic. Surprisingly, the situation was different at later stages and thus at HH stage $24(\mathrm{n}=10) c$-Lfng expression was present but restricted to the rostral region of the PSM (Figure 3C), whereas at $\mathrm{HH}$ stage $25(\mathrm{n}=7) c$-Lfng had disappeared completely from the PSM (Figure 3D). As mentioned above, at these stages of development there is still some Tbx6-positive PSM tissue (Figure 3E, F). We then examined the expression of two more genes regulated by Notch activity, c-Meso1 and c-Nrarp. Mesol is the homologue of mouse Mesp2, a critical factor for the formation of the epithelial somite [34] normally expressed in the rostral region of the PSM. At HH stage 24 Meso 1 was still present in the rostral PSM but by HH stage 25

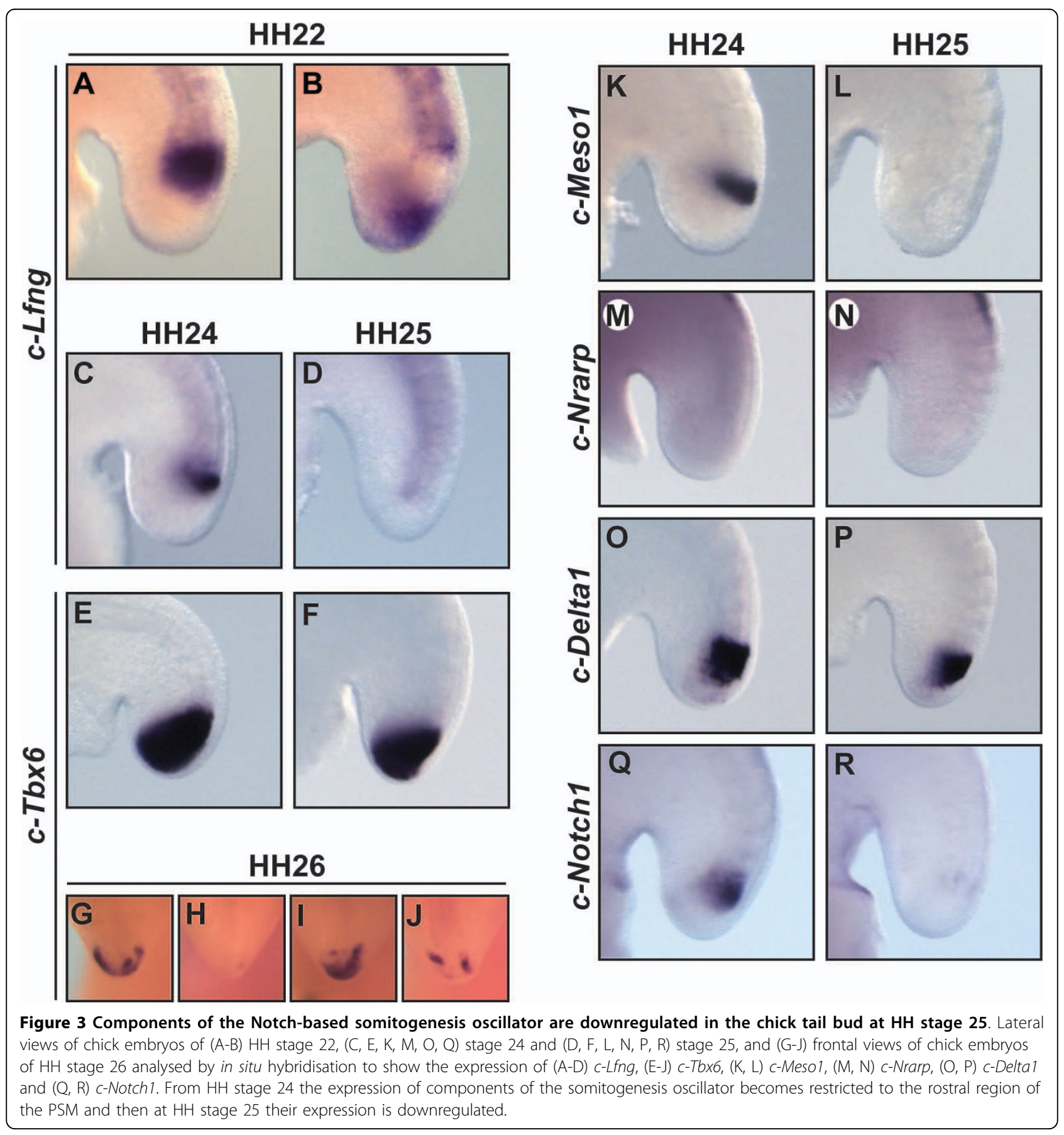


the expression was lost $(\mathrm{n}=10$, Figure $3 \mathrm{~K}, \mathrm{~L})$. Nrarp is another Notch-based cyclic gene $[35,36]$ and, surprisingly, it is no longer expressed in the PSM at either of these two stages of development $(n=9$, Figure $3 M, N)$. Lastly, we examined the expression of the Notch ligand Delta1 and the receptor Notch1 and found that whereas Delta1 $(\mathrm{n}=9)$ transcripts appear to remain strong at least in the median and rostral PSM, Notch1 $(\mathrm{n}=7)$ becomes downregulated (Figure 3O-R). Thus, from these expression patterns of the different Notch components, we conclude that at HH stage 24-25 Notch activity implicated in the mechanism of the oscillator in the PSM becomes first restricted to the rostral region of the PSM and is then abolished from the tissue.

Furthermore, we found that the expression of $c-T b x 6$ in the tail bud of different $\mathrm{HH}$ stage 26 chick embryos seems to diminish very irregularly until it disappears ( $\mathrm{n}$ $=10$, Figure $3 \mathrm{G}-\mathrm{J}$ ), in contrast to the organized pattern in which $T b x 6$ expression is normally downregulated in PSM cells as they become integrated into a new somite (Figure 1A-J). We tested if this irregular downregulation of $c-T b x 6$ could be temporally related to apoptosis, a process reported previously to be affecting the tail bud region [26,27,37-39]. To that end we performed TUNEL staining in chick embryos from $\mathrm{HH}$ stage 13 to stage 27 $(\mathrm{n}=34)$. This analysis clearly showed the existence of a localized domain of apoptosis in the chick tail bud affecting the whole area until $\mathrm{HH}$ stage 20-21 [Additional File 1] and then again at $\mathrm{HH}$ stage 25-26 [Additional File 1], which indeed could be a contributing factor to the elimination of the remaining $T b x 6$ positive PSM tissue that does not segment into somites.

\section{Onset of c-Raldh2 expression and retinoic activity in the chick tail bud}

As an alternative or additional possible mechanism contributing to the cessation of somite formation and tail bud growth we searched for patterns of expression that would be consistent with changes in the proliferation status of the precursor population. A number of reports have previously shown that Wnt3a is implicated in the generation of mesodermal tissues within the developing primitive streak and tail bud, and it plays a pivotal role in the normal development and proliferation of these structures [40-44]. In the absence of Wnt3a the growth of caudal structures is seriously impaired, as seen in the vestigial tail $(v t)$ mutant embryo, a hypomorphic allele with severely downregulated expression of Wnt3a in the tail bud that suffers severe caudal agenesis [40]. Similarly, when Wnt3a expression is downregulated by exposure to ectopic retinoic acid (RA) the embryo displays axial truncations [45-48]. A comparable phenotype is also observed in homozygous embryos of Cyp26A1-/because in the absence of this RA-degrading enzyme the tail bud becomes exposed to endogenous RA produced by the somites, which acts to downregulate Wnt3a in the tail bud [49-51]. Thus, we decided to re-examine by in situ hybridisation the temporal and spatial expression profile of members of Wnt and RA signalling pathways in the tail bud of the chick embryo at HH stage 20-24. Our analysis shows that $c-W n t 3 a$ is expressed in a broad area of the tail bud until HH stage 20, whereupon its expression is dramatically reduced to the very tip until it disappears at $\mathrm{HH}$ stage $24(\mathrm{n}=38$, Figure $4 \mathrm{~A}-\mathrm{E})$. A similar profile of expression is detected for the Wnt regulated gene, $c$-Fgf8 (data not shown). When we checked the expression of $c$-Raldh2 $(\mathrm{n}=27)$, which encodes an RA-producing enzyme, we found that it is not expressed in the tail bud at early stages (Figure 4F). However, from $\mathrm{HH}$ stage 21 we observed a previously unreported onset of $c$-Raldh 2 expression in the chick tail bud, which remained in this domain until later stages (Figure 4G-J). The transcripts for the enzyme cCyp26A1 involved in the catabolism and inactivation of RA were expressed in the tail bud at all stages analysed ( $\mathrm{n}=16$, Figure $4 \mathrm{~K}-\mathrm{O}$ ). The onset of Raldh 2 in the tail bud is an intriguing observation because it suggests that from $\mathrm{HH}$ stage 21 the chick tail bud might be exposed to endogenous RA produced in that very tissue. As mentioned above, there are examples showing there is a correlation between levels of RA and the expression of Fgf8 and Wnt3a [45-48,52-54].

This onset of Raldh2 in the tail bud could in theory have an effect on the proliferative status of the tissue and the cessation of the growth of the tail bud. To support this possibility we first investigated if this onset is associated with detectable RA activity. To that end we tested for RA activity in the tail bud by co-culturing embryonic samples of tail bud from different developmental stages on top of a monolayer of F9 cells stably transfected with a $1.8 \mathrm{~kb}$ promoter sequence of a RA-responding element coupled to the lacZ gene (F9-1.8 cells) [55]. When we co-cultured F9-1.8 cells with tail bud explants from $\mathrm{HH}$ stage 20 embryos, which are $c$-Raldh2-negative, lac $Z$ staining/RA activity was not detected ( $\mathrm{n}=7$, Figure $5 \mathrm{D})$, however, in the cultures incubated with tail bud explants from HH stage 21-26 embryos, which are c-Raldh2-positive, lac $Z$ staining/RA activity was detectable $(\mathrm{n}=8$, Figure 5E, F). To confirm that changes in the levels of RA lead to changes in both the expression of Wnt/FGF markers and the growth of the chick tail we decided to artificially reproduce the onset of Raldh2 in the tail bud by grafting beads soaked in 1.5-10 mM RA adjacent to the tail bud of $\mathrm{HH}$ stage 12-15 chick embryos $(\mathrm{n}=21)$ and then cultured them overnight for 12-15 hours. The treatment led to the extinction of both $c$-Fgf8 and $c$-Wnt3a expression in the tail bud (Figure $5 \mathrm{H}-\mathrm{J}$ and data not shown; $[45,47])$ and also caused a significant 


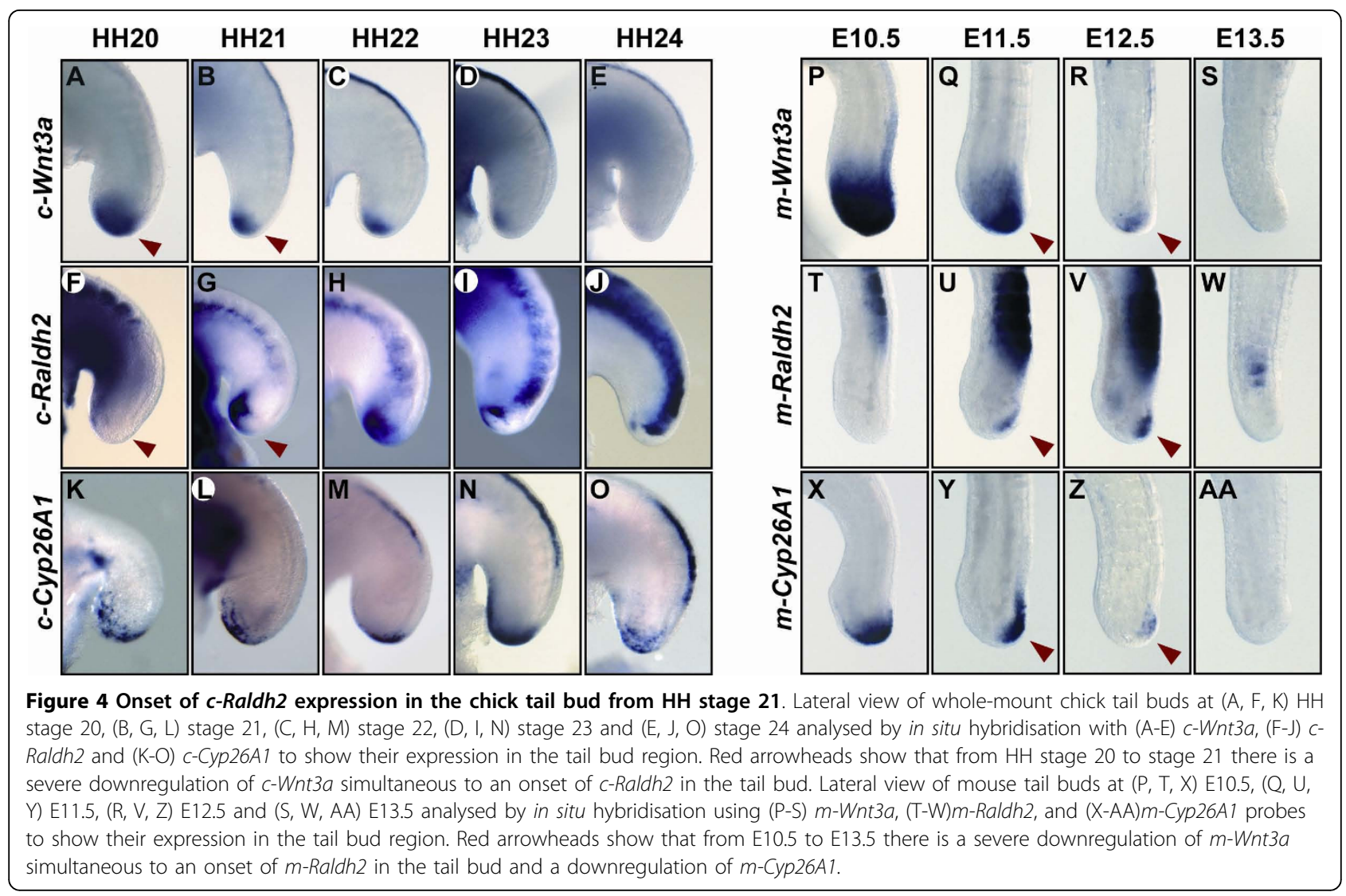

reduction in PSM growth, as compared to control samples $(\mathrm{t}$-test; $\mathrm{df}=17, \mathrm{P}<0.001$ for $1.5 \mathrm{mM} \mathrm{RA}$ and $\mathrm{df}=$ $20, P=0.004$ for $10 \mathrm{mM}$ RA; Figure $5 \mathrm{~K}, \mathrm{~L}$ ). In summary, our results indicate that endogenous RA derived from a late onset of Raldh2 expression in the chick tail bud may be implicated in the late stages of somitogenesis/axial elongation by controlling the expression of Wnt and FGF factors in this domain.

Finally, we also analysed the expression of several relevant genes in a collection of 10.5-13.5 days post-coitum (dpc) mouse embryos to see if this onset of RA in the tail bud is conserved. We observed that $m-W n t 3 a$ is expressed in a broad area of the tail bud until E11.5 whereupon its expression is dramatically reduced to the very tip at E12.5 until it finally disappears at E13.5 ( $\mathrm{n}=$ 14, Figure 4P-S). From E11.5 there is an onset of $m$-Raldh2 expression in the mouse tail bud $(\mathrm{n}=19$, Figure $4 \mathrm{~T}-\mathrm{W}$ ), although it is noticeably weaker than that observed in chick, as judged by the intensity of the staining compared with the expression detected in the somites. In addition, when we evaluated the endogenous retinoic acid activity in mouse tail bud explants from E12.5 using the F9-1.8 cells we were not able to detect retinoid activity (data not shown). However, in the mouse embryo there is an alternative source of RA. The size of the mouse PSM is quite small [Additional File 2], thus the RA-producing somites are located close to the tail bud and may act as a source of RA, which could therefore be affecting this tissue during somitogenesis. Because of this proximity the tail bud region needs to be constantly protected from this source of RA and if this protection is lost, for example in Cyp26A1-/embryos, then the tail bud becomes prematurely exposed to RA and the result is the generation of axial truncations [49-51]. Interestingly, we found that $m$ Cyp26A1 is reduced at E11.5 until it disappears $(\mathrm{n}=16$, Figure $4 \mathrm{X}$-AA), suggesting that once the protective expression of $m$-Cyp $26 A 1$ is downregulated then RA may also affect the mouse tail bud in the mouse as a result of the onset of $m$-Raldh 2 in the tail bud as well as $m$-Raldh2 from the somites.

\section{Discussion}

We report here that termination of the process of somitogenesis seems to be the result of a combination of events occurring in the paraxial mesoderm tissue and the precursor population of the tail bud (see schematic representation in Figure 5G). 


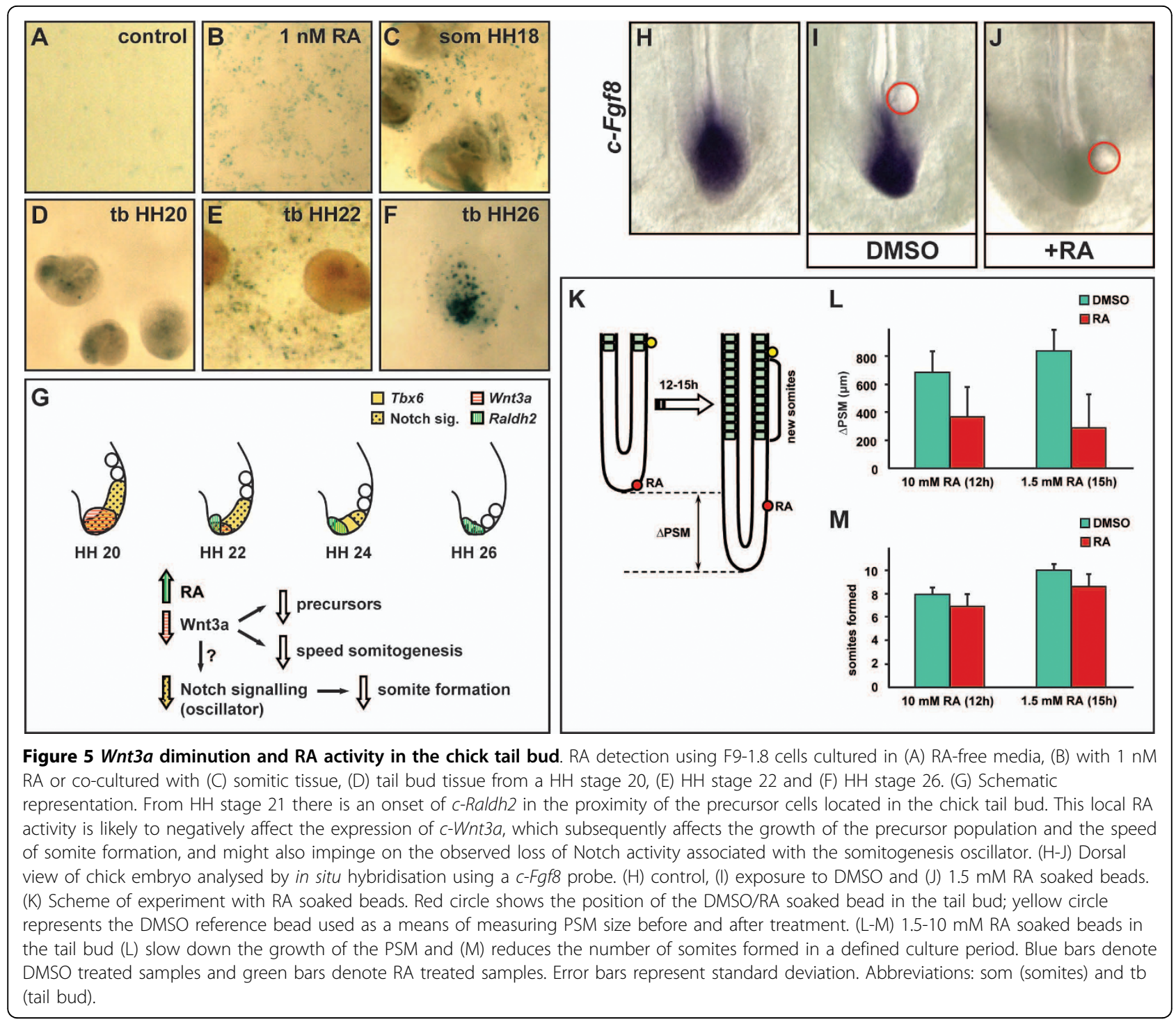

\section{Speed of somitogenesis and Wnt3a}

Our data shows that the termination of somitogenesis is not the consequence of an acceleration of the speed of somite formation. In fact, this speed remains constant during the formation of all somites except for the last few, which require a longer time. For example, our data shows that at $\mathrm{HH}$ stage 23 somite formation might require 150 minutes. Why somite formation takes longer at those late stages of development is still unknown. We think it could be a collateral effect related to the diminution of Wnt3a in the tail bud at these stages, since we have previously shown that when Wnt activity is attenuated in vitro the period of $c$ - Lfng oscillations is increased [33]. Interestingly, our data also indicates that there were consistently fewer somites formed in RAtreated embryos as compared to control embryos (Mann-Whitney Rank Sum Test; P $=<0.001$ for $1.5 \mathrm{mM}$
RA and $\mathrm{P}=0.009$ for $10 \mathrm{mM}$ RA; Figure $5 \mathrm{~K}, \mathrm{M}$ ), an effect that could be recapitulating in vitro the physiological slowing we observed at late stages of development (Figure 2), and which is coincident with the presence of RA activity in the tail bud and the concomitant downregulation of Wnt3a expression (Figure 4).

\section{The arrest of the somitic oscillator}

The examination of the number of somites formed at each specific stage using as reference the expression of Tbx6 in the PSM and Dact2/MyoD in the forming somite shows that chick somitogenesis is completed (5153 somites) at around $\mathrm{HH}$ stage 24-25, rather than at $\mathrm{HH}$ stage 22 [30]. Despite the fact that no further somites are formed, some Tbx6-positive PSM tissue remains at $\mathrm{HH}$ stage 24-25. This expression domain diminishes progressively until it disappears at $\mathrm{HH}$ stage 
26-27. These observations indicate that the paraxial mesoderm does not become fully segmented to the tip of the tail, as indeed proposed by Bellairs and colleagues more than two decades ago $[26,56]$. Nevertheless, by $\mathrm{HH}$ stage 26-27 the last formed somite is positioned adjacent to the tail tip. The gradual shift of position of the last formed somite towards the tail tip may be due to the morphological re-shaping of the tail bud that happens at these stages of development [39].

There must be a reason why the terminal PSM does not segment. Sanders et al. proposed that this limitation could be imposed by different reasons, including the local environment and the existence of apoptosis [26]. Tbx6 expression within this tissue indicates that it maintains its PSM genetic character even after somitogenesis has concluded. The results clearly indicate that, as judged by the patterns of expression of components of the Notch pathway, the somitogenesis oscillator is arrested at these stages of development. Thus, the expression of Notch components, such as $c$-Lfng, is initially lost in the caudal PSM and becomes restricted to the rostral half of the PSM (HH stage 24) until it disappears (HH stage 25). This would suggest that the same tissue that displayed the last oscillations in the caudal PSM did so prior to $\mathrm{HH}$ stage 24 , and as this tissue becomes displaced more rostrally it is also the last tissue to display non cyclic Notch activity implicated in boundary formation and thereby makes the last somitic border. We have recently shown that when all Notch activity is lost then somitogenesis is arrested [57]. The mechanism involved in the loss of Notch activity at these late stages and the subsequent arrest of the somitic oscillator is still unknown, although it is tempting to speculate that the downregulation of Wnt3a observed at HH stages 21-24 could also be implicated in this arrest because the expression of the ligand Delta1 in the caudal PSM has been shown to be dependent on Wnt3a, at least in the mouse embryo [58,59]. Also consistent with this hypothesis is the fact that when Wnt/FGF activities are temporally blocked after pharmacological treatment the expression of cyclic genes is arrested in the mouse $[33,60]$. It would be interesting to test this model during chick development by blocking Wnt/FGF activities long term and then analysing their morphological consequences.

\section{Last remaining PSM and apoptosis}

Since the last few Tbx6-positive PSM cells do not contribute to make additional somites the question arises what becomes of them. TUNEL staining at $\mathrm{HH}$ stages 25-26 is restricted to the terminal region of the tail [Additional File 1] [37,38], which suggests that at least part of this remaining unsegmented paraxial mesoderm population could be dying by programmed cell death, as previously suggested [27]. This possibility would be consistent with the irregular pattern of expression of $T b x 6$ observed at $\mathrm{HH}$ stage 26 . However, we cannot formally rule out the possibility that part of this population changes fate, loses $T b x 6$ and is incorporated in other neighbouring structures of the embryo. If current technical limitations can be overcome in the future, it would be very interesting to explore this possibility by following their fate.

\section{Endogenous RA and the tail bud}

We describe here an onset of Raldh2 in both the chick and mouse tail bud that at least in the case of the chick embryo is strong enough to generate detectable levels of RA, as scored by lacZ staining with the F9-1.8 RAresponding cell line. The precise temporal correlation between the onset of Raldh2 expression and RA activity in the chick tail bud, and the observed downregulation of Wnt $3 a$ suggests these events could be linked, as has been shown to be the case after addition of ectopic RA [45-48]. In addition, as discussed above, we think that the longer period of the somitogenesis oscillator is likely to be an indirect effect of this RA-mediated Wnt3a downregulation.

If endogenous RA is also implicated in the cessation of segmentation in the mouse embryo by downregulation of $W n t 3 a / F g f 8$ then the main source of this RA is probably the somites. In normal conditions the expression of Cyp26A1 in the mouse tail bud, which is regulated by trunk Hox (paralog group 13) and Cdx factors [61], prevents the diffusion of RA from the somites into the tissue and thereby prevents premature exposure of the progenitor population to RA. However, its removal in the Cyp26A1-/- mouse embryos allows endogenous RA to function unregulated in the mouse tail bud inducing dramatic abnormalities on the development of caudal structures including severe truncations [49-51]. The phenotype of this mouse mutant line is very similar to the sacral agenesis produced after teratological exposure to high levels of ectopic RA [62-65]. Thus, elevated retinoid activity, endogenous or ectopic, leads to a rapid and significant decrease in the expression of caudal markers, such as Wnt3a $[45,46,48-50]$. We think a similar elevated local retinoid activity, although highly regulated, could be affecting the tail bud in normal embryos at late stages of development due to the physiological downregulation of Cyp26A1, and which is concomitant with the onset of Raldh2 expression and the downregulation of Wnt3a and Fgf8.

\section{Open questions}

The signals responsible for the growth of the precursor population seem to be reversible, since transplanting chick and mouse tail bud cells from a late stage embryo 
to earlier stages results in the grafted tissue contributing to somites along the entire axis, as well as re-colonising the host tail bud after culture $[13,17,66]$. These results indicate that termination of axial elongation is likely to depend upon changes in the tissue environment in the tail bud rather than a loss of competence to self-renew. Further analyses will be required to generate comprehensive answers concerning the nature of the molecular and cellular changes in the tail bud at late stages of somitogenesis. These analyses should provide a better understanding of how the somitogenesis oscillator is arrested at these stages of development, how the growth of the precursor population is affected and how relevant the exposure to endogenous RA is to this process. The degree of conservation of each of these mechanisms in different species, and how they are each regulated will also contribute to explain the generation of the very varied and complex body plans displayed by different vertebrate species.

\section{Conclusions}

Our results show that the termination of the process of somitogenesis in the chick embryo is not due to acceleration in the speed of somite formation because it remains constant, except at late stages of development when it slows down. We found that when the chick embryo reaches its final number of somites at stage $\mathrm{HH} 24-25$ there is still some remaining unsegmented presomitic mesoderm, in which the expression of components of the somitogenesis oscillator is no longer dynamic, suggesting that at these stages of development the somitic oscillator is arrested. Finally, endogenous RA emanating from an onset of expression in the tail bud and/or from the somites is probably involved in the control of the process of somitogenesis, and in tail growth in general, by controlling the expression of Wnt3a and Fgf8.

\section{Methods}

\section{Embryos and in situ hybridisation}

White leg horn Gallus gallus eggs were sourced from Henry Stewart \& Co (Lincolnshire) and incubated at $38.5^{\circ} \mathrm{C}$ in a humidified incubator. Embryos were staged according to the Hamburger Hamilton (HH) developmental table [30] and by somite counting. Wild-type CD1 mouse (Mus musculus) embryos were obtained from timed mated pregnant females between 10.5 and 13.5 dpc (E10.5-E13.5). In situ hybridisation analysis was basically performed as described [67]. Proteinase K treatment for old chick embryos was as follows: $\mathrm{HH}$ stage 20, $20.5 \mathrm{~min}$; HH stage 21-22, $22 \mathrm{~min}$; HH stage 23-24, $24.5 \mathrm{~min}$; HH stage 24-25, $26 \mathrm{~min}$, HH stage 2627, $28 \mathrm{~min}, \mathrm{HH}$ stage 28, $29 \mathrm{~min}$. Images were captured on a Leica MZ16 APO microscope using a Jenoptik camera. All animals were handled in strict accordance with good animal practice as defined by the Home Office (UK) and local animal welfare bodies, and all animal work was approved by the ethical committee for experiments with animals of the University of Dundee (UK).

\section{Somite formation curve and PSM size measurements}

Eggs $(\mathrm{n}=105)$ were incubated at $38.5^{\circ} \mathrm{C}$ until they reached $\mathrm{HH}$ stage 8 (3-5 pairs of somites), then carefully windowed and the shell membrane above the embryo was removed and ink diluted 1:10 with Phosphate-buffered saline (PBS) was injected underneath the embryo to visualize the somites. The initial number of somites was counted. Eggs were then sealed with parafilm and incubated at $38.5^{\circ} \mathrm{C}$ for specific time periods and the final number of somites was recounted. For the latest stages (HH stage 23-26), somites were visualized and counted after $c$ Dact $2 / c M y o D$ double in situ hybridisation. The PSM was measured from the posterior boundary of the last formed somite to the end of the neural tube. The size of the PSM and of the last formed somite was measured using Carl Zeiss AxioVision 4 software and a grid of the Neubauer Improved counting chamber as a standard for the measurements.

\section{Apoptosis and manipulation of the Retinoid pathway}

For detection of apoptotic cells, the ApopTag Plus Peroxidase In situ kit (Chemicon) was used. For ectopic RA treatment 1.5-10 mM all-trans-RA or Dimethyl sulfoxide (DMSO) soaked beads were implanted in vivo in the tail bud region of $\mathrm{HH}$ stage 12-15 embryos, which were then incubated overnight before collecting the embryos for analysis. For RA detection F9 cells transfected with a $1.8 \mathrm{~kb}$ promoter sequence of the mouse retinoic acid $\beta 2$ receptor coupled to the $l a c Z$ gene were grown to confluence as described [55]. Chick embryos were dissected in PBS and the tail bud tip or last formed somites were isolated and placed on top of RA-responding cells for 10 minutes to allow their attachment. $0.5 \mathrm{ml}$ media was added and the cultures were incubated overnight at $38.5^{\circ} \mathrm{C}$ in a humidified incubator with $5 \% \mathrm{CO}_{2}$. Alternatively, a solution containing 1-10 nM RA was added in place of the explants as a control for detection of RA activity. LacZ activity was detected by X-Gal staining overnight at $37^{\circ} \mathrm{C}$ performed according to the protocol for $\beta$-Galactosidase reporter gene staining kit (Sigma).

Additional file 1: Supplementary Figure 1; Apoptosis in the chick tail bud. (A, B) Dorsal and (C-F) lateral views of chick embryos analysed by TUNEL staining to identify cell death in the chick tail bud at $\mathrm{HH}$ stages 13-26, showing there strong localised apoptosis in the tail bud of $\mathrm{HH}$ stage 13-19 and then again in the terminal region at $\mathrm{HH}$ stage 26. Click here for file

[http://www.biomedcentral.com/content/supplementary/1471-213X-1024-S1.TIFF ] 
Additional file 2: Supplementary Figure 2; Wnt3a diminution and RA activity in the mouse tail bud. (A-D) Lateral view of E10.5-E13.5 mouse tail buds analysed by in situ hybridisation using m-Tbx6. (E) Bar chart showing the size of the PSM (green bars) and the size of the last somite (red bars) at E10.5-13.5. (F) Bar chart showing the ratio PSM versus last somite during the same window of development calculated separately for each embryo and then the average ratio was calculated for each stage. Error bars represent standard deviation. Black dotted lines represent the variation of these parameters observed in the chick embryo from HH stage10 to stage 25, as shown in Figure 1. Click here for file

[ http://www.biomedcentral.com/content/supplementary/1471-213X-1024-S2.TIFF]

\section{Acknowledgements}

We are grateful to the members of the MM and JKD laboratories and especially to J. Kim Dale for her critical and generous participation in this project. We thank the groups of Paola Bovolenta, Astrid Buchberger, Domingos Henrique, David Ish-Horowicz, Susan Mackem, Gail Martin, Ivor Mason, Virginia Papaioannou and the Hubrecht Institute (Netherlands) for providing reagents. We also thank Marianne Reilly, Marie Pryde and Letitia Gibson for their administrative support and smiles, Stieneke van den Brink for technical advices and Kate Storey for discussions. MM holds an MRC Career Development Award.

\section{Author details}

'Division of Cell and Developmental Biology, College of Life Sciences, University of Dundee, Dow Street, Dundee, UK. ${ }^{2}$ The Roslin Institute and Royal Dick School of Veterinary Studies, University of Edinburgh, Roslin, UK.

\section{Authors' contributions}

MM designed the project and the experiments. GT, DW, ZF, MMc, RB and MM performed the experiments. GT, DW, ZF and MM analysed the data. MM wrote the manuscript and prepared the figures. All authors read and approved the final manuscript.

Received: 28 July 2009

Accepted: 25 February 2010 Published: 25 February 2010

\section{References}

1. Bryson-Richardson RJ, Currie PD: The genetics of vertebrate myogenesis. Nat Rev Genet 2008, 9:632-646.

2. Dequeant ML, Pourquie O: Segmental patterning of the vertebrate embryonic axis. Nat Rev Genet 2008, 9:370-382.

3. Holley SA: The genetics and embryology of zebrafish metamerism. Dev Dyn 2007, 236:1422-1449.

4. Christ B, Huang R, Scaal M: Amniote somite derivatives. Dev Dyn 2007, 236:2382-2396.

5. Catala M, Teillet MA, Le Douarin NM: Organization and development of the tail bud analyzed with the quail-chick chimaera system. Mech Dev 1995, 51:51-65.

6. Meinhardt $\mathrm{H}$ : Models of biological pattern formation: from elementary steps to the organization of embryonic axes. Curr Top Dev Biol 2008, 81:1-63.

7. limura T, Yang X, Weijer CJ, Pourquie O: Dual mode of paraxial mesoderm formation during chick gastrulation. Proc Natl Acad Sci USA 2007, 104:2744-2749.

8. Lopez-Sanchez C, Garcia-Martinez V, Schoenwolf GC: Localization of cells of the prospective neural plate, heart and somites within the primitive streak and epiblast of avian embryos at intermediate primitive-streak stages. Cells Tissues Organs 2001, 169:334-346.

9. Sawada K, Aoyama H: Fate maps of the primitive streak in chick and quail embryo: ingression timing of progenitor cells of each rostro-caudal axial level of somites. Int J Dev Biol 1999, 43:809-815.

10. Schoenwolf GC, Smith JL: Gastrulation and early mesodermal patterning in vertebrates. Methods Mol Biol 2000, 135:113-125.

11. Tam PP, Goldman D, Camus A, Schoenwolf GC: Early events of somitogenesis in higher vertebrates: allocation of precursor cells during gastrulation and the organization of a meristic pattern in the paraxial mesoderm. Curr Top Dev Biol 2000, 47:1-32.

12. Pasteels J: Etudes sur la gastrulation des vertebras meroblastiques. III. Oiseaux. IV Conclusions generales. Arch Biol 1937, 48:381-488.

13. Cambray N, Wilson V: Axial progenitors with extensive potency are localised to the mouse chordoneural hinge. Development 2002, 129:4855-4866.

14. Davis RL, Kirschner MW: The fate of cells in the tailbud of Xenopus laevis. Development 2000, 127:255-267.

15. Hatada Y, Stern CD: A fate map of the epiblast of the early chick embryo. Development 1994, 120:2879-2889.

16. Knezevic V, De Santo R, Mackem S: Continuing organizer function during chick tail development. Development 1998, 125:1791-1801.

17. McGrew MJ, Sherman A, Lillico SG, Ellard FM, Radcliffe PA, Gilhooley HJ, Mitrophanous KA, Cambray N, Wilson V, Sang H: Localised axial progenitor cell populations in the tail bud are not committed to a posterior Hox identity. Development 2008, 135:2289-2299.

18. Psychoyos D, Stern CD: Fates and migratory routes of primitive strak cells in the chick embryo. Development 1996, 122:1523-1534.

19. Schoenwolf GC, Garcia-Martinez V, Dias MS: Mesoderm movement and fate during avian gastrulation and neurulation. Dev Dyn 1992, 193:235-248.

20. Selleck MA, Stern CD: Fate mapping and cell lineage analysis of Hensen's node in the chick embryo. Development 1991, 112:615-626.

21. Cooke J, Zeeman EC: A clock and wavefront model for control of the number of repeated structures during animal morphogenesis. $J$ Theor Biol 1976, 58:455-476.

22. Cinquin O: Understanding the somitogenesis clock: what's missing?. Mech Dev 2007, 124:501-517.

23. Mara A, Holley SA: Oscillators and the emergence of tissue organization during zebrafish somitogenesis. Trends Cell Biol 2007, 17:593-599.

24. Ozbudak EM, Pourquie O: The vertebrate segmentation clock: the tip of the iceberg. Curr Opin Genet Dev 2008, 18:317-323.

25. Richardson MK, Allen SP, Wright GM, Raynaud A, Hanken J: Somite number and vertebrate evolution. Development 1998, 125:151-160

26. Sanders EJ, Khare MK, Ooi VC, Bellairs R: An experimental and morphological analysis of the tail bud mesenchyme of the chick embryo. Anat Embryol (Berl) 1986, 174:179-185.

27. Mills CL, Bellairs R: Mitosis and cell death in the tail of the chick embryo. Anat Embryol (Berl) 1989, 180:301-308.

28. Bellairs R: The tail bud and cessation of segmentation in the chick embryo. Somites in Developing Embryos. NATO ASI series Plenum Press, New YorkBellairs R, Ede DA, Lash JW 1986, 118:161-178.

29. Ohta S, Suzuki K, Tachibana K, Tanaka H, Yamada G: Cessation of gastrulation is mediated by suppression of epithelial-mesenchymal transition at the ventral ectodermal ridge. Development 2007, 134:4315-4324.

30. Hamburger $\mathrm{V}$, Hamilton $\mathrm{HL}$ : A series of normal stages in the development of the chick embryo. J Morphol 1951, 88:49-92.

31. Gomez C, Ozbudak EM, Wunderlich J, Baumann D, Lewis J, Pourquie O: Control of segment number in vertebrate embryos. Nature 2008, 454:335-339

32. McGrew MJ, Dale JK, Fraboulet S, Pourquie O: The lunatic fringe gene is a target of the molecular clock linked to somite segmentation in avian embryos. Curr Biol 1998, 8:979-982

33. Gibb S, Zagorska A, Melton K, Tenin G, Vacca I, Trainor P, Maroto M, Dale JK: Interfering with Wnt signalling alters the periodicity of the segmentation clock. Dev Biol 2009, 330:21-31.

34. Saga Y: Segmental border is defined by the key transcription factor Mesp2, by means of the suppression of Notch activity. Dev Dyn 2007, 236:1450-1455.

35. Wright D, Ferjentsik Z, Chong SW, Qiu X, Jiang YJ, Malapert $P$, Pourquié O, Van Hateren N, Wilson SA, Franco C, Gerhardt H, Dale JK, Maroto M: Cyclic Nrarp mRNA expression is regulated by the somitic oscillator but Nrarp protein levels do not oscillate. Dev Dyn 2009, 238:3043-3055.

36. Sewell W, Sparrow DB, Smith AJ, Gonzalez DM, Rappaport EF, Dunwoodie SL, Kusumi K: Cyclical expression of the Notch/Wnt regulator Nrarp requires modulation by DII3 in somitogenesis. Dev Biol 2009, 329:400-409. 
37. Hirata M, Hall BK: Temporospatial patterns of apoptosis in chick embryos during the morphogenetic period of development. Int J Dev Biol 2000, 44:757-768.

38. Miller SA, Briglin A: Apoptosis removes chick embryo tail gut and remnant of the primitive streak. Dev Dyn 1996, 206:212-218.

39. Schoenwolf GC: Morphogenetic processes involved in the remodeling of the tail region of the chick embryo. Anat Embryol (Berl) 1981, 162:183-197.

40. Greco TL, Takada S, Newhouse MM, McMahon JA, McMahon AP, Camper SA: Analysis of the vestigial tail mutation demonstrates that Wnt3a gene dosage regulates mouse axial development. Genes Dev 1996, 10:313-324.

41. Takada S, Stark KL, Shea MJ, Vassileva G, McMahon JA, McMahon AP: Wnt3 a regulates somite and tailbud formation in the mouse embryo. Genes Dev 1994, 8:174-189.

42. Tam PP, Trainor PA: Specification and segmentation of the paraxial mesoderm. Anat Embryol (Berl) 1994, 189:275-305.

43. Wilson V, Beddington RS: Cell fate and morphogenetic movement in the late mouse primitive streak. Mech Dev 1996, 55:79-89.

44. Yoshikawa Y, Fujimori T, McMahon AP, Takada S: Evidence that absence of Wnt-3a signaling promotes neuralization instead of paraxial mesoderm development in the mouse. Dev Biol 1997, 183:234-242.

45. Chan BW, Chan KS, Koide T, Yeung SM, Leung MB, Copp AJ, Loeken MR, Shiroishi T, Shum AS: Maternal diabetes increases the risk of caudal regression caused by retinoic acid. Diabetes 2002, 51:2811-2816.

46. Iulianella A, Beckett B, Petkovich M, Lohnes D: A molecular basis for retinoic acid-induced axial truncation. Dev Biol 1999, 205:33-48.

47. Shum AS, Poon LL, Tang WW, Koide T, Chan BW, Leung YC, Shiroishi T, Copp AJ: Retinoic acid induces down-regulation of Wnt-3a, apoptosis and diversion of tail bud cells to a neural fate in the mouse embryo. Mech Dev 1999, 84:17-30.

48. Yasuda $Y$, Konishi $H$, Kihara $T$, Tanimura $T$ : Discontinuity of primary and secondary neural tube in spina bifida induced by retinoic acid in mice. Teratology 1990, 41:257-724.

49. Abu-Abed S, Dolle P, Metzger D, Beckett B, Chambon P, Petkovich M: The retinoic acid-metabolizing enzyme, CYP26A1, is essential for normal hindbrain patterning, vertebral identity, and development of posterior structures. Genes Dev 2001, 15:226-240.

50. Abu-Abed S, Dolle P, Metzger D, Wood C, MacLean G, Chambon P, Petkovich M: Developing with lethal RA levels: genetic ablation of Rarg can restore the viability of mice lacking Cyp26a1. Development 2003, 130:1449-1459.

51. Sakai $Y$, Meno C, Fujii H, Nishino J, Shiratori H, Saijoh $Y$, Rossant J, Hamada H: The retinoic acid-inactivating enzyme CYP26 is essential for establishing an uneven distribution of retinoic acid along the anterioposterior axis within the mouse embryo. Genes Dev 2001, 15:213-225.

52. Diez del Corral R, Olivera-Martinez I, Goriely A, Gale E, Maden M, Storey K: Opposing FGF and retinoid pathways control ventral neural pattern, neuronal differentiation, and segmentation during body axis extension. Neuron 2003, 40:65-79.

53. Sirbu IO, Duester G: Retinoic-acid signalling in node ectoderm and posterior neural plate directs left-right patterning of somatic mesoderm. Nat Cell Biol 2006, 8:271-277.

54. Zhao X, Duester G: Effect of retinoic acid signaling on Wnt/beta-catenin and FGF signaling during body axis extension. Gene Expr Patterns 2009, 9:430-435.

55. Sonneveld $E_{1}$ Brink van den $C E$, Leede van der BJ, Maden M, Saag van der PT: Embryonal carcinoma cell lines stably transfected with mRARbeta2lacZ: sensitive system for measuring levels of active retinoids. Exp Cell Res 1999, 250:284-297.

56. Bellairs R, Sanders EJ: Somitomeres in the chick tail bud: an SEM study. Anat Embryol (Berl) 1986, 175:235-240.

57. Ferjentsik Z, Hayashi S, Dale JK, Bessho Y, Herreman A, De Strooper B, del Monte $G$, de la Pompa $J L$, Maroto M: Notch is a critical component of the mouse somitogenesis oscillator and is essential for the formation of the somites. PLoS Genetics 2009, 5(9):e1000662.

58. Galceran J, Sustmann C, Hsu SC, Folberth S, Grosschedl R: LEF1-mediated regulation of Delta-like1 links Wnt and Notch signaling in somitogenesis. Genes Dev 2004, 18:2718-2723.

59. Hofmann M, Schuster-Gossler K, Watabe-Rudolph M, Aulehla A, Herrmann BG, Gossler A: WNT signaling, in synergy with T/TBX6, controls
Notch signaling by regulating Dll1 expression in the presomitic mesoderm of mouse embryos. Genes Dev 2004, 18:2712-2717.

60. Niwa Y, Masamizu Y, Liu T, Nakayama R, Deng CX, Kageyama R: The initiation and propagation of Hes7 oscillation are cooperatively regulated by Fgf and notch signaling in the somite segmentation clock. Dev Cell 2007, 13:298-304.

61. Young T, Rowland JE, Ven van de C, Bialecka M, Novoa A, Carapuco M, van Nes J, de Graaff W, Duluc I, Freund JN, Beck F, Mallo M, Deschamps J: Cdx and Hox genes differentially regulate posterior axial growth in mammalian embryos. Dev Cell 2009, 17:516-526.

62. Alles AJ, Sulik KK: A review of caudal dysgenesis and its pathogenesis as illustrated in an animal model. Birth Defects Orig Artic Ser 1993, 29:83-102.

63. Kessel M: Respecification of vertebral identities by retinoic acid. Development 1992, 115:487-501.

64. Osmond M: The effects of retinoic acid on early heart formation and segmentation in the chick embryo. Formation and Differentiation of Early Embryonic Mesoderm Plenum Press, New YorkBellairs R, et al 1992, 275-297.

65. Padmanabhan $\mathrm{R}$ : Retinoic acid-induced caudal regression syndrome in the mouse fetus. Reprod Toxicol 1998, 12:139-151.

66. Tam PP, Tan SS: The somitogenetic potential of cells in the primitive streak and the tail bud of the organogenesis-stage mouse embryo. Development 1992, 115:703-715.

67. Henrique D, Adam J, Myat A, Chitnis A, Lewis J, Ish-Horowicz D: Expression of a Delta homologue in prospective neurons in the chick. Nature 1995, 375:787-790.

doi:10.1186/1471-213X-10-24

Cite this article as: Tenin et al:: The chick somitogenesis oscillator is arrested before all paraxial mesoderm is segmented into somites. BMC Developmental Biology 2010 10:24

\section{Submit your next manuscript to BioMed Central and take full advantage of:}

- Convenient online submission

- Thorough peer review

- No space constraints or color figure charges

- Immediate publication on acceptance

- Inclusion in PubMed, CAS, Scopus and Google Scholar

- Research which is freely available for redistribution

Submit your manuscript at www.biomedcentral com/submit
C) Biomed Central 